\title{
miR-598 acts as a tumor suppressor in human gastric cancer by targeting IGF-IR
}

This article was published in the following Dove Press journal: OncoTargets and Therapy

\author{
$\mathrm{Na} \mathrm{Liu'}$ \\ Hua Yang ${ }^{2}$ \\ Hong Wang ${ }^{3}$ \\ 'Intensive Care Unit, Shandong \\ Provincial Third Hospital, Shandong, \\ China; ${ }^{2}$ Intensive Care Unit, Chiping \\ County People's Hospital, Shandong, \\ China; ${ }^{3}$ Department of General \\ Surgery, Shandong Provincial Third \\ Hospital, Shandong, China
}

\begin{abstract}
Background: In recent years, the aberrant expression of miR-598 in tumorigenesis has been demonstrated, as well as the fact that the IGF-1R pathway is also involved in the development of human gastric cancer (GC). The present study aimed to investigate the molecular mechanisms underlying miR-598-regulated IGF-1R expression in human GC.

Materials and methods: We analyzed the expression of miR-598 and IGF-1R in GC samples and cells, and evaluated the clinical significance of miR-598 and IGF-1R in GC patients. Furthermore, in vitro and in vivo assays were used to investigate the molecular mechanisms of miR-598 and IGF-1R.

Results: miR-598 expression was frequently downregulated in GC tissues and cells, and significantly correlated with poor prognosis, vascular invasion, TNM stage, and lymph node metastases as well as IGF-1R expression. The overexpression of miR-598 obviously inhibited cell proliferation, migration, invasion, and induced cell cycle arrest in the G1/S phase, and increased the apoptosis of GC cells. The overexpression of miR-598 also significantly inhibited ERK1/2 and Akt phosphorylation level. In vivo assay validated the inhibitory effect of miR-598 on tumor growth. Further studies showed that miR-598 inhibited IGF-1R protein expression by directly targeting its $3^{\prime}$-UTR. Besides, over-expression of IGF-1R reversed the inhibitory effects of miR-598, while suppression of IGF-1R expression showed inverse effects.
\end{abstract}

Conclusion: miR-598 suppresses GC cell proliferation, migration and invasion by directly targeting IGF-1R expression. Thus, miR-598 may be a useful target for GC patients.

Keywords: miR-598, IGF-1R, gastric cancer, proliferation, migration, invasion suppressor

\section{Introduction}

Gastric cancer (GC) is one of the leading causes of cancer-related mortality, and poses a serious threat to individuals' health in China. ${ }^{1,2}$ Recently, some etiologic mechanisms involved in the development and progression of GC have been thoroughly investigated, including genetic and epigenetic alterations. ${ }^{3,4}$ However, current therapeutic methods, involving surgery or radio/chemotherapy, are unsatisfactory due to the advanced stage at diagnosis of GC. In addition, malignant or advanced GC is characterized as malignant proliferation, vascular invasion, and lymphatic metastasis. ${ }^{5,6}$ Thus, it is essential to investigate novel targets to effectively treat GC patients.

miRNAs are a kind of small non-coding RNA, and play an important role in the development of GC. ${ }^{7,8}$ miRNAs are able to precisely bind the $3^{\prime}$-UTR of their target mRNAs, and trigger the degradation or translation inhibition of mRNAs. ${ }^{9,10}$ It has been demonstrated that the expression of miRNA is markedly correlated with the proliferation and metastasis of tumors. For instance, miR-122-5p inhibits tumor cell proliferation and induces apoptosis by targeting MYC in GC cells. ${ }^{11}$ Notably, miR-598 expression
Correspondence: Hong Wang

Department of General Surgery, Shandong Provincial Third Hospital, 12 Central Wuying Hill Road, Jinan 25003I, Shandong, China Email wanghongslsy@I63.com
OncoTargets and Therapy 2018: I 2911-2923

(c) (i) (ㅇ) 2018 Liu et al. This work is published and licensed by Dove Medical Press Limited. The full terms of this license are available at https://www.dovepress.com/terms.php

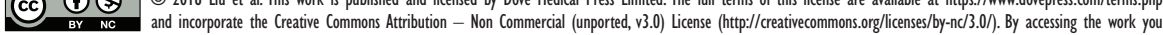
hereby accept the Terms. Non-commercial uses of the work are permitted without any further permission from Dove Medical Press Limited, provided the work is properly attributed. For permission for commercial use of this work, please see paragraphs 4.2 and 5 of our Terms (https://www.dovepress.com/terms.php). 
level was demonstrated to be low in some cancer tissues and cells. It has been reported that miR-598 overexpression repressed the proliferation, migration, and invasion of osteosarcoma cells. ${ }^{12}$ However, the specific roles and mechanisms of miR-598 in GC progression are rarely explored. Besides, IGF-1R was identified to be highly expressed in a variety of human cancers including squamous cell carcinoma of head and neck, endometrial carcinoma, and papillary thyroid cancer. ${ }^{13-15}$ In our previous study, IGF-1R functioned as a tumor promoter in GC cell survival and development. ${ }^{16}$ However, it is not clear whether miR-598 can regulate IGF-1R expression in GC.

In the present study, we analyzed miR-598 and IGF-1R expression levels in GC samples and cells, and evaluated the role of miR-598 and IGF-1R in the tumorigenesis of GC cells. Then, we explored the relationship between miR-598 and clinicopathological features using a large GC sample and evaluated its prognostic value in GC patients. Furthermore, in vitro and in vivo assays were used to investigate its specific molecular mechanisms.

\section{Materials and methods Ethics statement}

Ethical approval was obtained from the Ethics Committee of Shandong Provincial Third Hospital. Patients enrolled in this study signed written informed consent. All procedures were subject to the Declaration of Helsinki.

\section{Patients and tissue samples}

A total of 90 patients (56 males and 34 females; median age, 50 years; range, 18-79 years) with GC, who underwent gastrectomy in the Department of General Surgery, Shandong Provincial Third Hospital and Shandong Cancer Hospital between March 2011 and December 2012, were enrolled in the present study. Adjacent non-tumor tissues located at least $5 \mathrm{~cm}$ from tumors were selected as controls. All cases were classified according to the World Health Organization's pathological classification (2010) of gastric tumors. Written informed consent was obtained from each patient and the present study was approved by the Ethics Committee of Shandong Provincial Third Hospital. The specimens were obtained after surgical resection, immediately frozen, and stored in liquid nitrogen.

\section{GC cell lines}

The GC cell lines MKN-28, BGC-823, and AGS were obtained from American Type Culture Collection (Manassas, VA, USA). Human gastric mucosal epithelial cell line GES-1 was obtained from Shandong University Cancer Hospital. Cells were routinely cultured in DMEM (Thermo Fisher Scientific, Waltham, MA, USA) containing 10\% FBS (HyClone Laboratories Inc., Logan, UT, USA) at $37^{\circ} \mathrm{C}$ in a humidified $5 \% \mathrm{CO}_{2}$ atmosphere. HEK293T cells were obtained from Jinan University and were grown in DMEM supplemented with $10 \% \mathrm{FBS}$ in a $5 \% \mathrm{CO}_{2}$ incubator that was maintained at $37^{\circ} \mathrm{C}$. The use of these cell lines was approved by the Ethics Committee of Shandong Provincial Third Hospital.

\section{Transfection}

Cell transfection was conducted in cells using Lipofectamine 2000 (Thermo Fisher Scientific) according to the manufacturer's instructions. Briefly, cells were cultured to $70 \%$ confluence, and resuspended in serum-free DMEM. Negative control miRNAs (miR-NC), miR-598 mimics for miR-598 up-regulation, and pc-DNA3.1-IGF-1R plasmids for IGF-1R overexpression were diluted in OPTI-MEM (Thermo Fisher Scientific), which was then added to diluted Lipofectamine 2000. Following incubation for $20 \mathrm{~min}$ at room temperature, the mixture was added into the cell suspension. Following incubation at $37^{\circ} \mathrm{C}$ and $5 \% \mathrm{CO}_{2}$ for $6 \mathrm{~h}$, the transfection mixture was replaced with DMEM with $10 \%$ FBS.

For IGF-1R silencing, IGF-1R siRNA lentiviral vectors were constructed by inserting IGF-1R siRNA sequences into the GV248 lentiviral vector (GeneChem Company, Shanghai, China), then the viral supernatants were collected and filtered $48 \mathrm{~h}$ after the transfection. Finally, the expression of IGF-1R was confirmed by Western blot.

\section{RT-qPCR}

RNA was isolated using TRIzol (Thermo Fisher Scientific) following the manufacturer's protocols. The first strand cDNA was compounded using a Tianscript RT kit (Tiangen Biotech., Beijing, China). PCR amplifications for mRNA were performed with the TaqMan Human MiRNA Assay kit (Genecopoeia, Guangzhou, China) and the SYBR Premix Ex Taq ${ }^{\text {TM }}$ kit (TaKaRa, Shiga, Japan) in ABI 7300 system (Thermo Fisher Scientific). GAPDH was employed as reference genes to normalize the expression. U6 snRNA or GAPDH was used as internal control. The relative expression levels were calculated by the equation $2-\Delta \Delta \mathrm{CT}$.

\section{Western blot analysis}

The total protein was lysed from GC cells using RIPA solution (Sangon, Shanghai, China) and quantitated with BCA kit (Beyotime, Shanghai, China). An amount of $20 \mu \mathrm{g}$ of total protein was heated for $5 \mathrm{~min}$ and then separated by SDS-PAGE. 
The separated gels were transferred onto a PVDF membrane (EMD Millipore, Billerica, MA, USA). The transferred PVDF membrane was incubated with $5 \%$ nonfat milk in PBS containing $0.05 \%$ Tween-20 (PBST) for $1 \mathrm{~h}$ and then incubated with primary antibody at $25^{\circ} \mathrm{C}$ for $4 \mathrm{~h}$. After being washed four times with PBST, the membrane was incubated with HRP conjugated secondary antibody for another $2 \mathrm{~h}$. Detection was performed by chemiluminescent ECL detection kit (Thermo Fisher Scientific). The primary antibodies and the HRP conjugated second antibodies were purchased from Santa Cruz Biotechnology Inc., Dallas, TX, USA.

\section{Cell proliferation assay}

In brief, cells $(2 \times 104$ cells/well) in different groups were seeded into 96-well culture plates and cultured in RPMI 1640 medium containing 10\% FBS. After transfection for 24, 48 or 72 h, MTT reagent (Sigma-Aldrich Co., St Louis, MO, USA) was added to each well, followed by incubation at $37^{\circ} \mathrm{C}$ for an additional $4 \mathrm{~h}$. Subsequently, $150 \mu \mathrm{L}$ DMSO (SigmaAldrich Co.) was added to dissolve the crystals for $10 \mathrm{~min}$ at $37^{\circ} \mathrm{C}$. The spectrometric absorbance at $490 \mathrm{~nm}$ was measured by an EnSpire Multimode Plate Reader (PerkinElmer Inc., Waltham, MA, USA).

\section{FACS analysis}

After transfection for $24 \mathrm{~h}$, cells were firstly fixed in ice-cold $70 \%$ ethanol and then stained by PBS containing propidium iodide (PI)-Annexin V $(50 \mu \mathrm{g} / \mathrm{mL})$ and RNase A $(100 \mu \mathrm{g} / \mathrm{mL})$ for DNA analysis using flow cytometry analysis on a BD FACS Calibur system (FACScan; BD Biosciences, San Jose, CA, USA). Percentage of the cells in the different phases of cellular cycle was measured using the CellQuest software version 3.3 (BD Biosciences).

\section{Cell apoptosis assay}

Cell apoptosis was measured using an Annexin V-PI apoptosis detection kit (BD556547M; BD Biosciences). Following different treatment, cells were incubated with FITC-Annexin V $(5 \mu \mathrm{L})$ for $15 \mathrm{~min}$ at room temperature in the dark, and then with PI $(5 \mu \mathrm{L})$ for $5 \mathrm{~min}$ at $4^{\circ} \mathrm{C}$ in the dark, prior to analysis by flow cytometry.

\section{Cell migration and invasion assays}

Cells ( $5 \times 104$ for migration assays and $2 \times 105$ for invasion assays) were seeded into the upper chamber in serum-free medium. Culture medium containing 10\% FBS was added to the lower chamber as the chemoattractant. After the cells were incubated in a humidified incubator at $37^{\circ} \mathrm{C}$ for $24 \mathrm{~h}$ (migration assay) or $36 \mathrm{~h}$ (invasion assay), cells on the upper surface of the membrane were removed by scraping with a cotton swab, whereas cells attached to the lower surface were fixed with $4 \%$ paraformaldehyde and stained with $0.1 \%$ crystal violet for $10 \mathrm{~min}$. Five randomly selected fields of the fixed cells were imaged and counted using an X71 light inverted microscope (magnification $\times 200$; Olympus Corporation, Tokyo, Japan).

\section{Luciferase reporter assay}

To predict the potential targets of miR-598, bioinformatics analysis was performed with TargetScan and miRanda. HEK293T cells were used to perform the luciferase reporter assay. Wild-type (Wt)-IGF-1R 3'-UTR, mutated (Mut)IGF-1R 3'-UTR, or control luciferase reporter plasmid was co-transfected with miR-598 mimics or miR-NC using Lipofectamine 3000 (Thermo Fisher Scientific). Luciferase activity was measured by SecrePair Dual-Luciferase Reporter System (Genecopoeia).

\section{In vivo tumorigenesis assay}

$\mathrm{Balb} / \mathrm{c}$ nude mice were purchased from Shandong University (Jinan, Shandong, China) and maintained under SPF conditions. All experiments involving animals were performed in accordance with the Guide for the Administration of Affairs Concerning Experimental Animals, the national guideline for animal experiments. Cells were suspended in culture medium. A $160 \mu \mathrm{L}$ sample of medium containing $1 \times 10^{7}$ cells was injected into the dorsal flank of nude mice subcutaneously. The growth of tumor was monitored every week. Tumor volume was assessed by measuring the length (L) and width $(\mathrm{W})$ using calipers (tumor volume, $\mathrm{mm}^{3}=0.5 \times \mathrm{L} \times \mathrm{W}^{2}$ ). After 3 weeks, the mice were euthanized and the tumors were excised, measured, and photographed. In vivo experiments and animal protocol were approved by Ethics Committee (Animal Care and Use Department) of Shandong Provincial Third Hospital.

\section{Statistical analysis}

For prognostic analysis, the univariate and multivariate Cox regression model was used to identify the independent prognostic predictors of overall survival (OS). The recurrencefree survival (RFS) was defined as the time from diagnosis of GC to first locoregional or distant recurrence. The OS was the time from GC diagnosis to death. All statistical tests were performed using two-tailed distribution and $P<0.05$ was considered statistically significant. SPSS 19.0 software was used to perform statistical analysis. 


\section{Results}

\section{MiR-598 is downregulated in GC tissues and cells}

To figure out the role of miR-598 in the development of GC, RT-qPCR was carried out to detect the expression of miR-598 in GC tissues and adjacent non-tumor tissues. As shown in Figure 1A and B, miR-598 expression level was obviously downregulated in 90 cases of GC tissues compared with adjacent non-tumor tissues $(P<0.05)$. Then, we detected the expression level of miR-598 in GC cell lines (MKN-28, BGC-823, and AGS) and gastric mucosal epithelial cell line GES-1. As illustrated in Figure 1A and B, we demonstrated that miR-598 expression level was also significantly downregulated in three GC cell lines in comparison with GES-1 $(P<0.05)$.

\section{IGF-IR is overexpressed in GC tissues and cells}

Subsequently, we detected the expression levels of IGF-1R mRNA and protein using RT-qPCR and Western blot respectively in GC tissues and cells. We found the expression levels of IGF-1R mRNA and protein were significantly higher in GC tissues than those in matched non-tumor tissues $(P<0.05$, Figure $1 \mathrm{~A}-\mathrm{C})$. In addition, the expression levels of IGF-1R mRNA and protein were also significantly higher in MKN28, BGC-823 and AGS cells that those in GES 1 cells $(P<0.05$, Figure $1 \mathrm{~A}-\mathrm{C})$. In view of the similar expression model in MKN-28, BGC-823, and AGS cell lines, we selected MKN-28 and BGC-823 cells for further experiments.

\section{Association of miR-598 and IGF-IR with clinicopathological characteristics}

Furthermore, we analyzed the correlation between miR598, IGF-1R expression and clinicopathological characteristics of GC patients. We found that both miR-598 and IGF-1R expression was correlated with histological grade, vascular invasion, lymph node metastasis, and TNM stage (all $P<0.05$, Table 1). However, no statistically significant differences were found between miR-598, IGF-1R expression and other variables, such as gender, age, and tumor size (all $P>0.05$, Table 1). Besides, we explored the relationship of miR-598 and IGF-1R expression with RFS or OS in GC patients. The Kaplan-Meier analysis revealed that miR-598 or IGF-1R expression level was associated with OS (log rank $=4.384, P=0.036$; log rank $=6.785, P=0.009$; respectively; Figure $2 \mathrm{~A}$ and $\mathrm{B}$ ) and RFS (log rank $=12.42, P<0.001$; $\log$ rank $=12.60, P<0.001$; respectively; Figure $2 \mathrm{C}$ and $\mathrm{D}$ ) in GC patients. Additionally, univariate and multivariate Cox analysis revealed that lymph node metastasis, TNM stage, miR-598, and IGF-1R mRNA and protein expression were identified as independent risk factors (all $P<0.05$, Table 2). These results implied that miR-598 might be a potential marker for prognosis of GC patients.

\section{miR-598 inhibits the proliferation, tumorigenicity, migration, and invasion of GC cells}

In this study, miR-598 mimics were transfected into MKN-28 and BGC-823 cell lines. RT-qPCR confirmed the expression of miR-598 was increased after transfection of miR-598
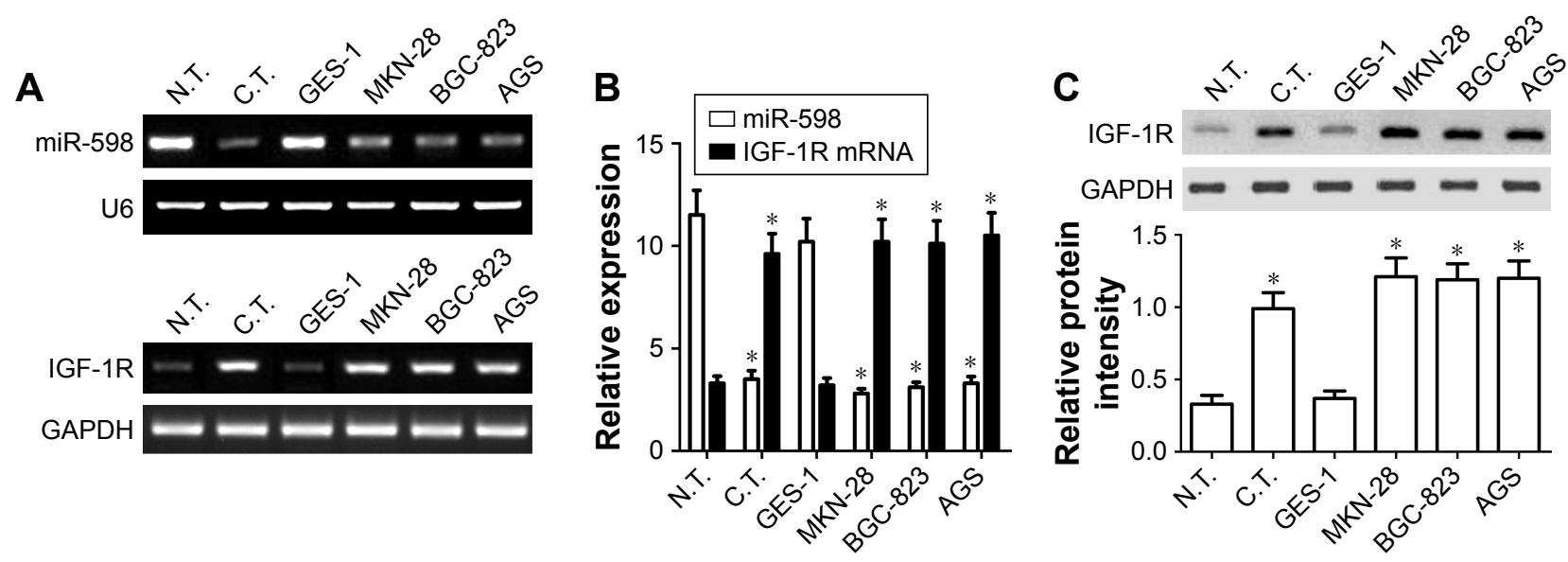

Figure I miR-598 and IGF-IR expression in gastric cancer (GC) tissues and cells.

Notes: (A) RT-PCR was performed to measure the expression of miR-598 and IGF-IR mRNA in GC tissues (C.T.), normal tissues (N.T.), normal GES-I cell, MKN-28, and BGC-823 cells. (B) The expression of miR-598 was normalized to U6, and levels of mRNA and proteins were normalized to GAPDH in each sample. Data are presented as mean \pm SD of at least three independent experiments. $* P<0.05$ vs N.T. or GES-I cells. (C) Western blot was performed to measure the expression of IGF-IR protein in C.T., N.T., normal GES-I cell, MKN-28, and BGC-823 cells. 
Table I Correlation of miR-598 and IGF-IR expression with GC clinicopathological variables

\begin{tabular}{|c|c|c|c|c|c|c|c|}
\hline Variables & $\mathbf{N}$ & miR-598 & $P$-value & IGF-IR mRNA & $P$-value & IGF-IR protein & $P$-value \\
\hline \multicolumn{8}{|l|}{ Age } \\
\hline$<50$ & 45 & $3.55 \pm 0.45$ & 0.532 & $10.91 \pm 1.11$ & 0.632 & $1.18 \pm 0.16$ & 0.563 \\
\hline$\geq 50$ & 45 & $3.25 \pm 0.51$ & & $11.12 \pm 1.08$ & & $1.03 \pm 0.14$ & \\
\hline \multicolumn{8}{|l|}{ Gender } \\
\hline Male & 56 & $3.68 \pm 0.31$ & 0.512 & $12.19 \pm 1.31$ & 0.356 & $1.07 \pm 0.17$ & 0.427 \\
\hline Female & 34 & $2.93 \pm 0.45$ & & $9.04 \pm 0.96$ & & $1.15 \pm 0.14$ & \\
\hline \multicolumn{8}{|l|}{ Tumor size } \\
\hline$<5 \mathrm{~cm}$ & 55 & $3.76 \pm 0.39$ & 0.284 & $10.03 \pm 1.07$ & 0.227 & $1.03 \pm 0.15$ & 0.199 \\
\hline$\geq 5 \mathrm{~cm}$ & 35 & $2.83 \pm 0.26$ & & $12.56 \pm 1.35$ & & $1.21 \pm 0.12$ & \\
\hline \multicolumn{8}{|l|}{ Histological grade } \\
\hline Well/moderate & 52 & $3.77 \pm 0.45$ & $0.039 *$ & $9.44 \pm 0.98$ & $0.045^{*}$ & $0.97 \pm 0.10$ & $0.049 *$ \\
\hline Poor & 38 & $2.89 \pm 0.33$ & & $13.14 \pm 1.65$ & & $1.28 \pm 0.12$ & \\
\hline \multicolumn{8}{|l|}{ Vascular invasion } \\
\hline Positive & 50 & $2.76 \pm 0.29$ & $0.033^{*}$ & $13.37 \pm 1.33$ & $0.029 *$ & $1.31 \pm 0.12$ & $0.028^{*}$ \\
\hline Negative & 40 & $4.20 \pm 0.43$ & & $9.11 \pm 0.91$ & & $0.84 \pm 0.09$ & \\
\hline \multicolumn{8}{|c|}{ Lymph node metastasis } \\
\hline Present & 61 & $2.65 \pm 0.35$ & $0.014 *$ & $13.3| \pm| .43$ & $0.018^{*}$ & $1.33 \pm 0.14$ & $0.007^{*}$ \\
\hline Absent & 29 & $4.9 I \pm 0.47$ & & $6.15 \pm 0.68$ & & $0.66 \pm 0.06$ & \\
\hline \multicolumn{8}{|l|}{ TNM stage } \\
\hline I-II & 33 & $4.66 \pm 0.56$ & $0.003 *$ & $6.89 \pm 0.59$ & $0.004^{*}$ & $0.56 \pm 0.09$ & $0.002^{*}$ \\
\hline III-IV & 57 & $2.67 \pm 0.29$ & & $13.38 \pm 1.66$ & & $I .4 I \pm 0.1 \mathrm{I}$ & \\
\hline
\end{tabular}

Note: *Statistically significant.

Abbreviation: GC, gastric cancer.
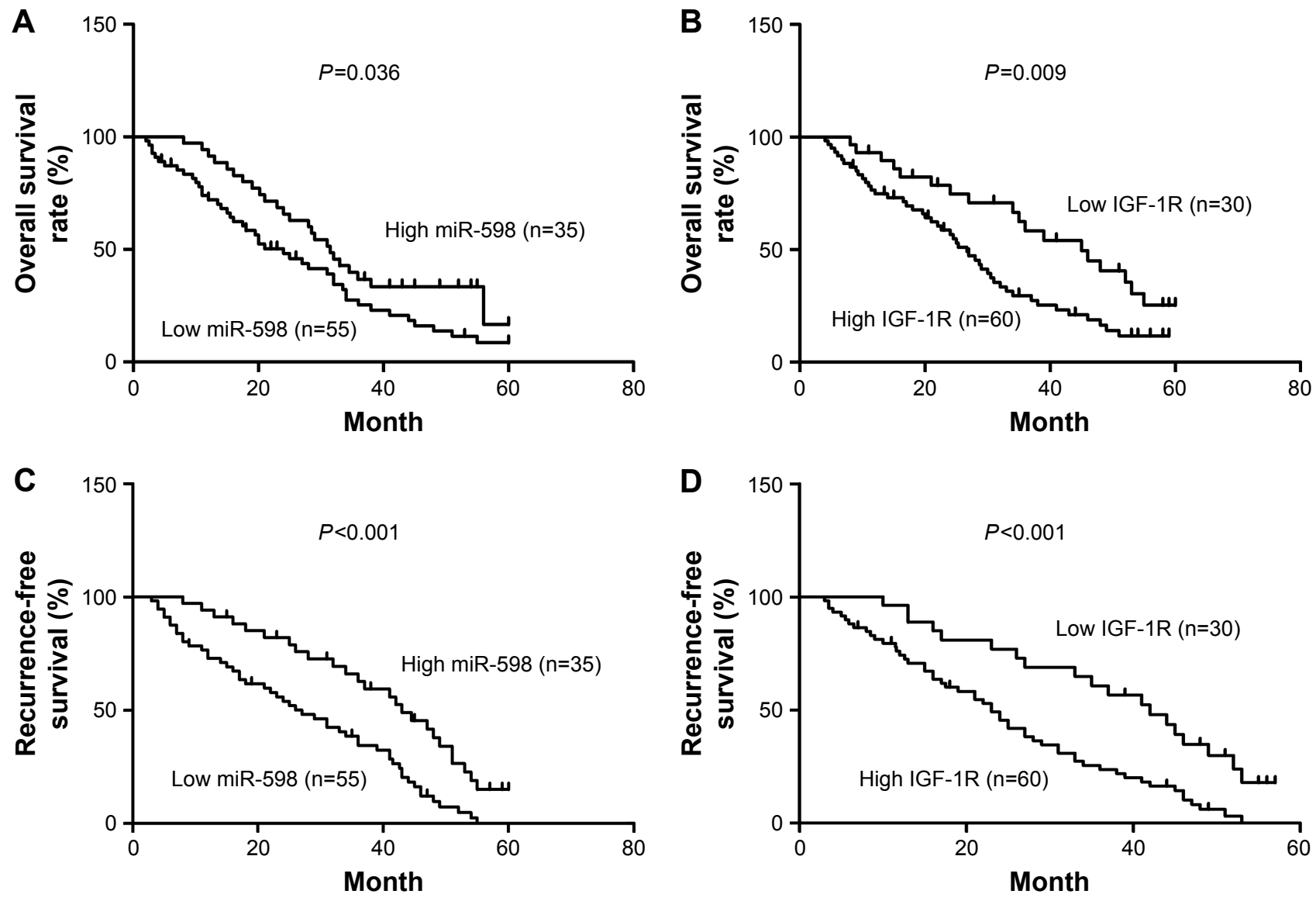

Figure 2 Correlation of miR-598 and IGF-IR expression with prognosis of gastric cancer (GC) patients.

Notes: (A, B) Kaplan-Meier analysis of overall survival in patients with different expressions of miR-598 or IGF-IR. The difference between these two groups is significant based on the log rank test. (C, D) Kaplan-Meier analysis of recurrence-free survival analysis in patients with different expressions of miR-598 or IGF-IR. The difference between these two groups is significant based on the log rank test. 
Table 2 Univariate and multivariate Cox regression analysis of overall survival of GC patients $(n=90)$

\begin{tabular}{|c|c|c|c|c|c|c|}
\hline \multirow[t]{2}{*}{ Variables } & \multicolumn{3}{|c|}{ Univariate analysis } & \multicolumn{3}{|c|}{ Multivariate analysis } \\
\hline & HR & $95 \% \mathrm{Cl}$ & $P$-value & HR & $95 \% \mathrm{Cl}$ & $P$-value \\
\hline Gender (male vs female) & 1.099 & $0.629-1.619$ & 0.970 & & & \\
\hline Age, years ( $\leq 50$ vs $>50)$ & 0.992 & $0.669-1.473$ & 0.969 & & & \\
\hline Tumor size $(\mathrm{cm},>5$ vs $\leq 5)$ & 1.445 & $0.647-3.226$ & 0.369 & & & \\
\hline Histological grade (poor vs well/moderate) & 1.375 & $0.743-2.546$ & 0.311 & & & \\
\hline Lymph node metastasis (present vs absent) & 1.564 & $1.109-2.352$ & $0.016 *$ & 1.787 & $1.056-3.021$ & $0.030 *$ \\
\hline Vascular invasion (positive vs negative) & 1.719 & $1.007-2.934$ & $0.047^{*}$ & 1.290 & $0.990-1.680$ & 0.059 \\
\hline TNM stage $(\mathrm{III}+\mathrm{IV}$ vs I+II) & 2.213 & $1.288-3.80 \mid$ & $0.004 *$ & 2.720 & $1.395-5.305$ & $0.003 *$ \\
\hline miR-598 expression (low vs high) & 2.166 & $1.124-4.175$ & $0.021 *$ & 1.899 & $1.151-3.132$ & $0.012^{*}$ \\
\hline IGF-IR mRNA expression (high vs low) & 2.331 & I.195-4.545 & $0.013 *$ & 2.091 & $1.202-3.637$ & $0.009 *$ \\
\hline IGF-IR protein expression (high vs low) & 2.201 & I.139-4.255 & $0.019 *$ & 2.113 & $|| 87-3.76 \mid$. & $0.011 *$ \\
\hline
\end{tabular}

Note: *Statistically significant.

Abbreviations: GC, gastric cancer; HR, hazard ratio.

mimics as compared with miR-NC (Figure 3A). MTT assay further showed that the ectopic expression of miR-598 obviously inhibited the proliferation level of MKN-28 and BGC-823 cells compared with their controls (both $P<0.05$, Figure 3B). Subsequently, we investigated the effect of miR-598 on the regulation of cell cycle. The cell cycle analysis revealed that the ectopic expression of miR-598 significantly induced cell cycle arrest in the G1/S phase in MKN-28 and BGC-823 cells compared with their respective controls (both $P<0.05$, Figure 3C). Flow cytometry revealed that the ectopic expression of miR-598 significantly induced cell apoptosis of MKN-28 and BGC-823 cells compared with their controls (both $P<0.05$, Figure 3D). The results revealed that the ectopic miR-598 expression inhibits the proliferation of GC cells. In view of in vitro assays, we further investigated whether miR-598 could affect tumor growth in vivo. MKN-28 and BGC-823 cells stably expressing miR-598 or miR-NC were injected subcutaneously into nude mice. We found that the average tumor volume of MKN-28 and BGC-823 cells transfected with miR-598 mimics was significantly smaller than those in the miR-NC group (Figure 3E).

Then, we conducted transwell assay to evaluate the effect of miR-598 on the migration and invasion of MKN-28 and BGC-823 cells. Results showed that overexpression of miR-598 significantly reduced the migration and invasion of MKN-28 and BGC-823 cells (Figure 4A and B). Overall, these results indicated that miR-598 serves as a tumor suppressor in GC cells.

\section{miR-598 inhibits the phosphorylation level of ERKI/2 and Akt of GC cells}

Because ERK1/2 and Akt pathways were demonstrated to be involved in IGF-1R signaling-induced proliferation, migration, and invasion, ${ }^{17,18}$ we further detected the expression of phosphorylated ERK1/2 and Akt. We found that the phosphorylation level of ERK1/2 and Akt in miR-598overexpressing MKN-28 and BGC-823 cells was significantly decreased compared with miR-NC group (both $P<0.05$, Figure 4C), indicating that miR-598 inhibits the phosphorylation level of ERK1/2 and Akt of GC cells.

\section{miR-598 inhibits IGF-IR expression by directly targeting its $3^{\prime}$-UTR}

In order to elucidate the target genes of miR-598 in GC cells, we performed informatics analysis using TargetScan online. Of various candidates, IGF-1R showed the most complementary sequences with miR-598 (Figure 5A). Therefore, we chose IGF-1R for further experiments. To validate the interactions, we conducted luciferase activity reporter assay with Wt-IGF-1R-3'-UTR or Mut-IGF-1R-3'-UTR reporter plasmids. We found that overexpression of miR-598 significantly repressed the luciferase activity in HEK293T cells transfected with Wt-IGF-1R-3'-UTR but not Mut-IGF-1R-3'UTR plasmid (Figure 5B and C). Furthermore, Western blot analysis revealed overexpression of miR-598 significantly decreased the expression of IGF-1R protein in HEK293T cells with miR-598 mimics (Figure 5D). Subsequently, the correlation between miR-598 and IGF-1R protein in GC samples was investigated. We demonstrated a negative correlation between miR-598 and IGF-1R protein expression in GC samples $\left(R^{2}=0.7268, P<0.001\right.$; Figure 5E). In addition, in vivo assay identified over-expression of miR-598 repressed the expression of IGF-1R protein in tumor tissues with MKN-28 or BGC-823 cells containing miR-598 mimics (Figure 5F). These findings suggested that miR-598 inhibits IGF-1R expression by directly targeting its $3^{\prime} \mathrm{UTR}$. 

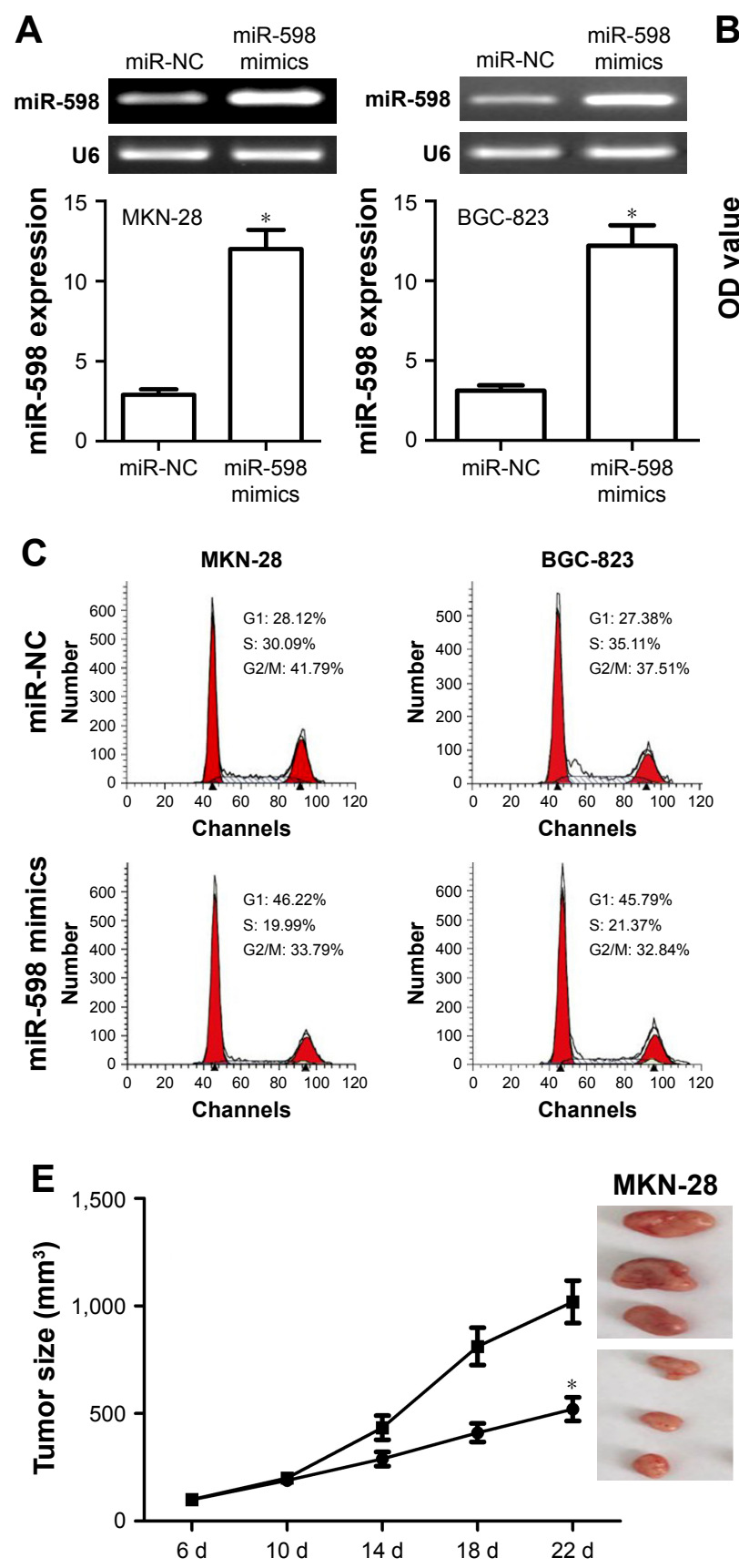

miR-598 mimics
B
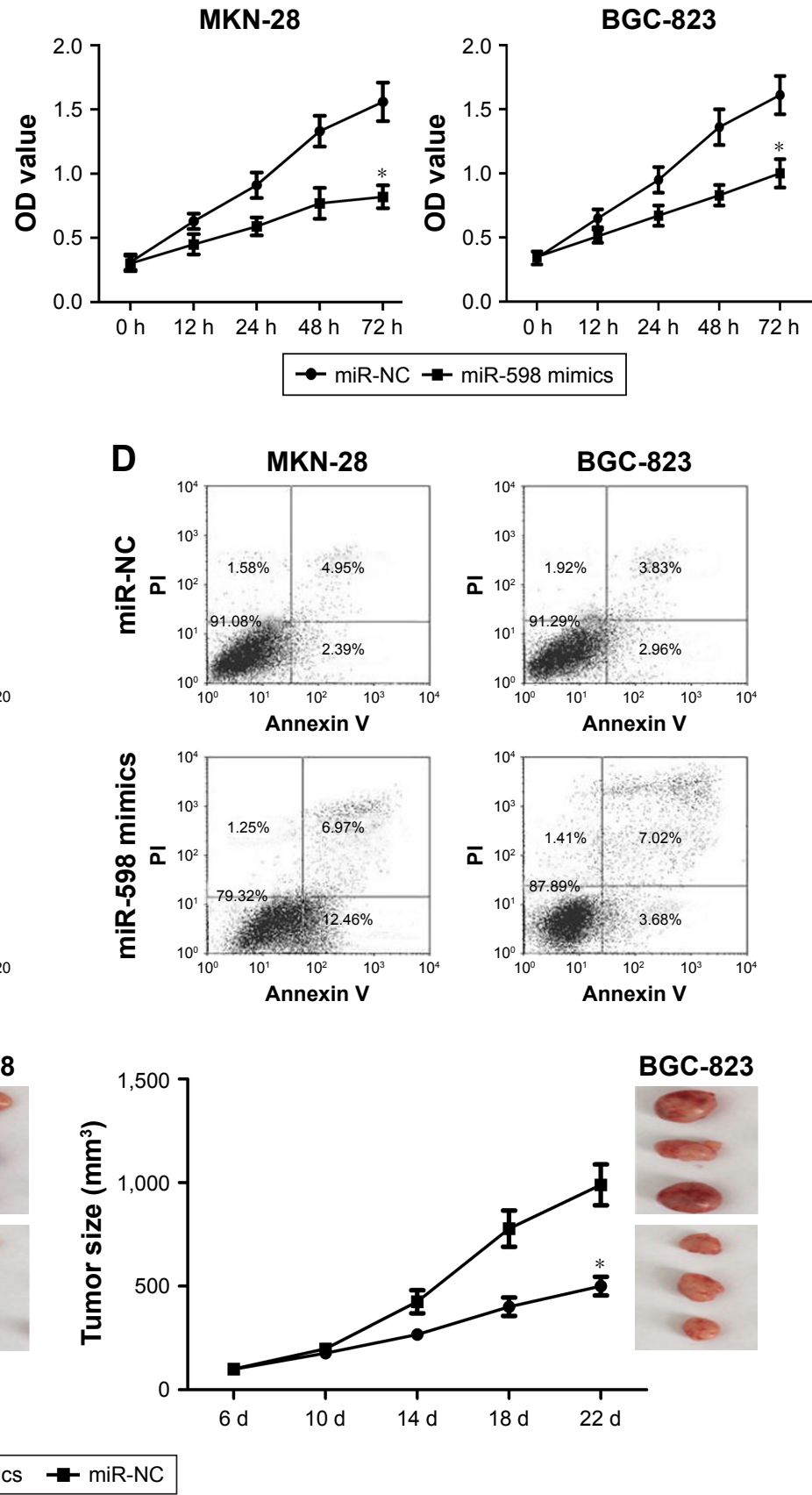

Figure 3 miR-598 inhibits cell proliferation and cell cycle in gastric cancer (GC) cells.

Notes: (A) miR-598 mimics were transfected into MKN-28 and BGC-823 cell lines to overexpress miR-598, and then miR-598 expression level was detected by RT-PCR and RT-qPCR assay. (B) Cell proliferation was determined in MKN-28 and BGC-823 cells by MTT assay. (C) Cell cycle was determined in MKN-28 and BGC-823 cells by FACS analysis. (D) Cell apoptosis was determined in MKN-28 and BGC-823 cells by flow cytometry analysis. Cells were transfected with miR-598 mimics or negative control miRNAs (miR-NC). (E) MKN-28 or BGC-823 cells stably transfected with miR-598-expressing plasmids or empty vector were subcutaneously injected into nude mice (three nude mice for experiment group, and three nude mice for control group) and tumor volumes were measured every week. Tumors were resected and measured at different time-points. The data were represented by mean \pm SD. $* P<0.05$, vs miR-NC.

Abbreviation: $\mathrm{PI}$, propidium iodide.

\section{IGF-IR overexpression reverses the inhibitory effects of miR-598}

To determine whether miR-598 repressed the progression of GC by targeting IGF-1R, we restored the expression of
IGF-1R by transfection with IGF-1R plasmids. Western blot showed that IGF-1R protein expression was obviously up-regulated in MKN-28 or BGC-823 cells with IGF-1R plasmids when compared with vector control 
A
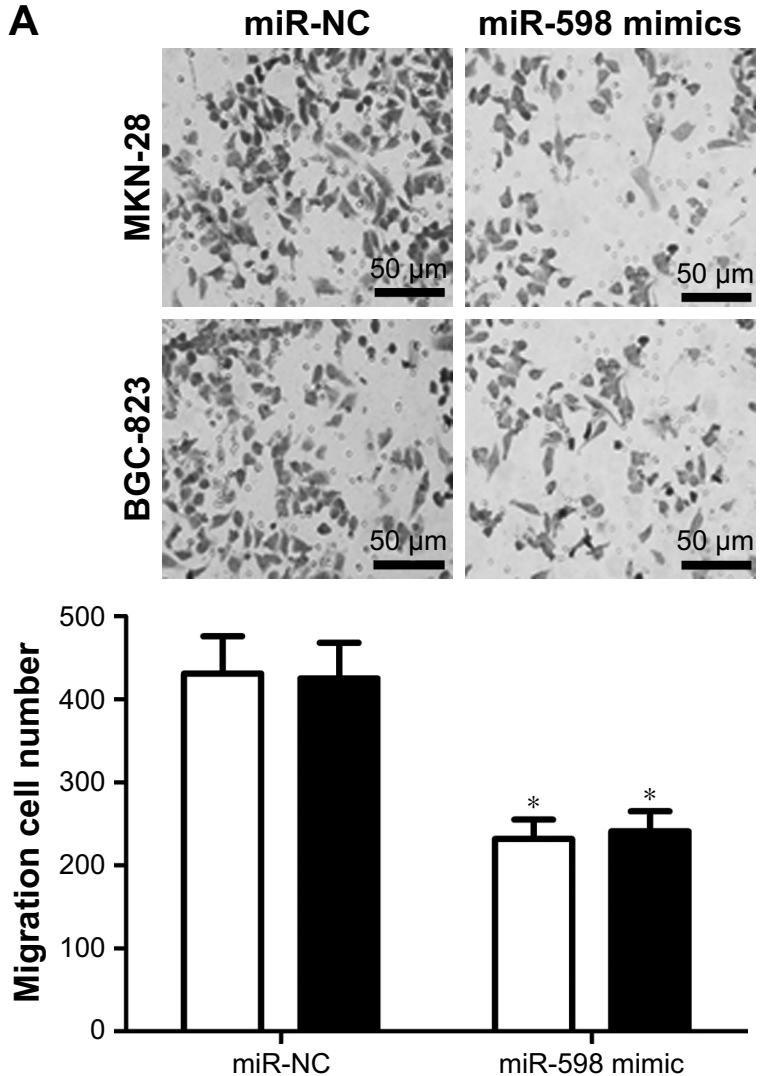

B

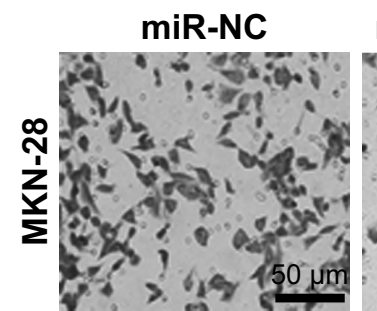

miR-598 mimics
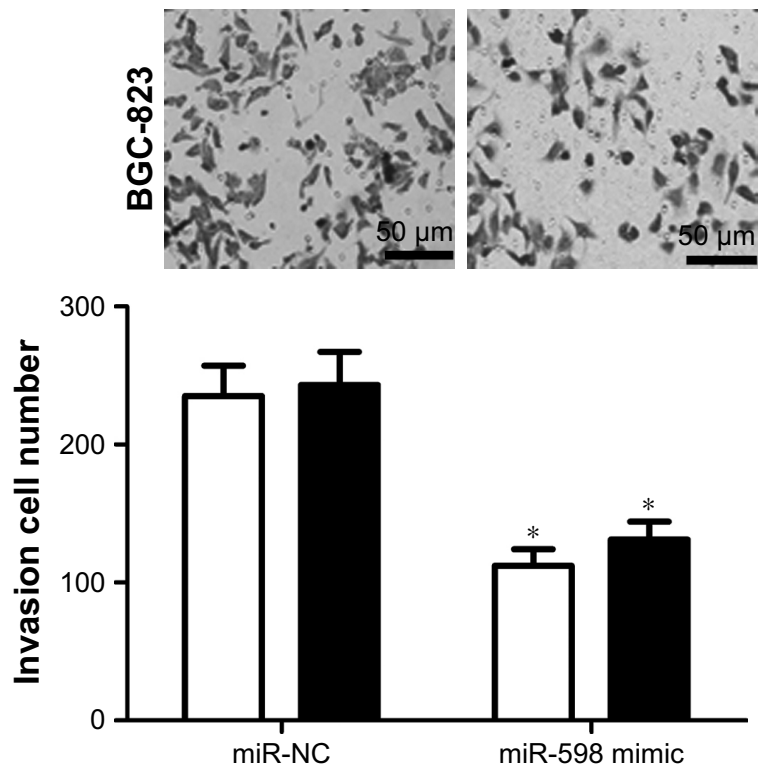

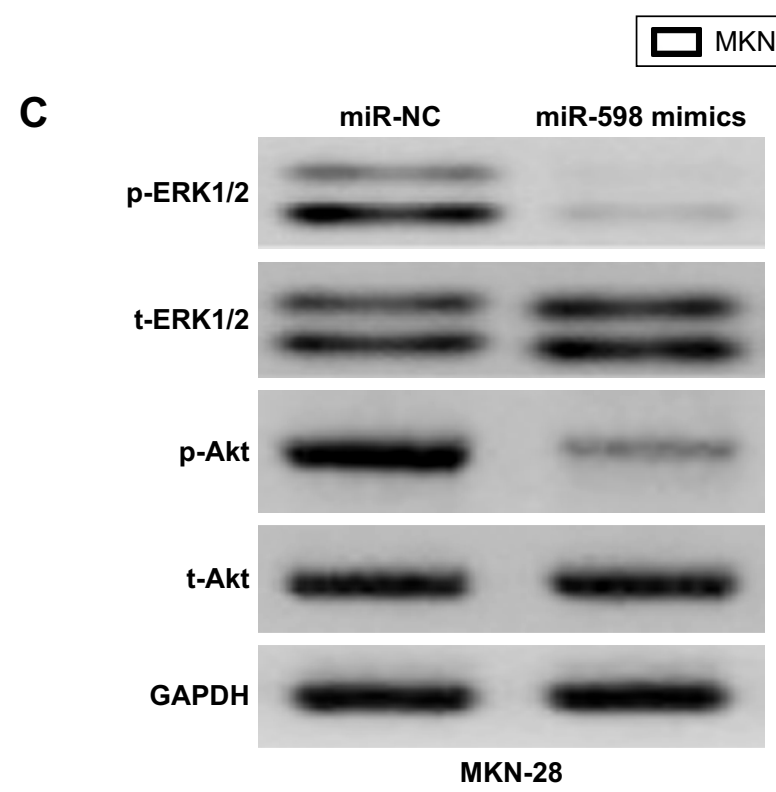

BGC-823

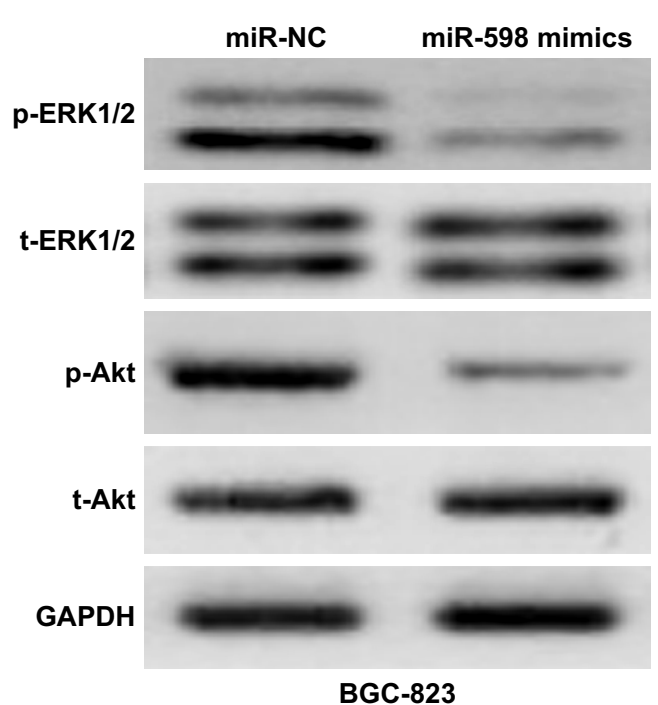

Figure 4 miR-598 inhibits gastric cancer (GC) cell migration, invasion, ERKI/2, and Akt phosphorylation.

Notes: (A) Cell migration assay was determined in MKN-28 and BGC-823 cells by transwell assay. (B) Cell invasion assay was determined in MKN-28 and BGC-823 cells by transwell assay. (C) ERKI/2 and Akt phosphorylation levels were detected by Western blot, and levels of proteins were normalized to GAPDH. Cells were transfected with miR-598 mimics, or control miRNAs (miR-NC). The data were represented by mean \pm SD. $* P<0.05$, vs miR-NC. The black scale bar $=50 \mu$ m.

Abbreviations: p-ERKI/2, phosphorylated ERKI/2; p-Akt, phosphorylated Akt; t-ERKI/2, total ERKI/2; t-Akt, total Akt.

(Figure 6A). Further studies showed that miR-598 overexpression inhibited the proliferation of MKN-28 or BGC-823 cells, while restoration of IGF-1R expression rescued miR-598-inhibited cell proliferation (Figure 6B).
Finally, we carried out transwell assay, and observed that overexpression of IGF-1R obviously effectively increased the migration and invasion of MKN-28 or BGC-823 cells (Figure 6C and D). 
A

$\begin{array}{ll}\text { Wt-IGF-1R-3'-UTR } & 5^{\prime} \ldots \text { UUAUGAUGACGUG...3' } \\ \text { hsa-miR-598 } & 3^{\prime} \ldots \text { GUUGCUACUGCAA...5 } \\ \text { Mut-IGF-1R-3'-UTR } & 5^{\prime} \ldots \text { UUAUGAGCACAUG...3' }\end{array}$
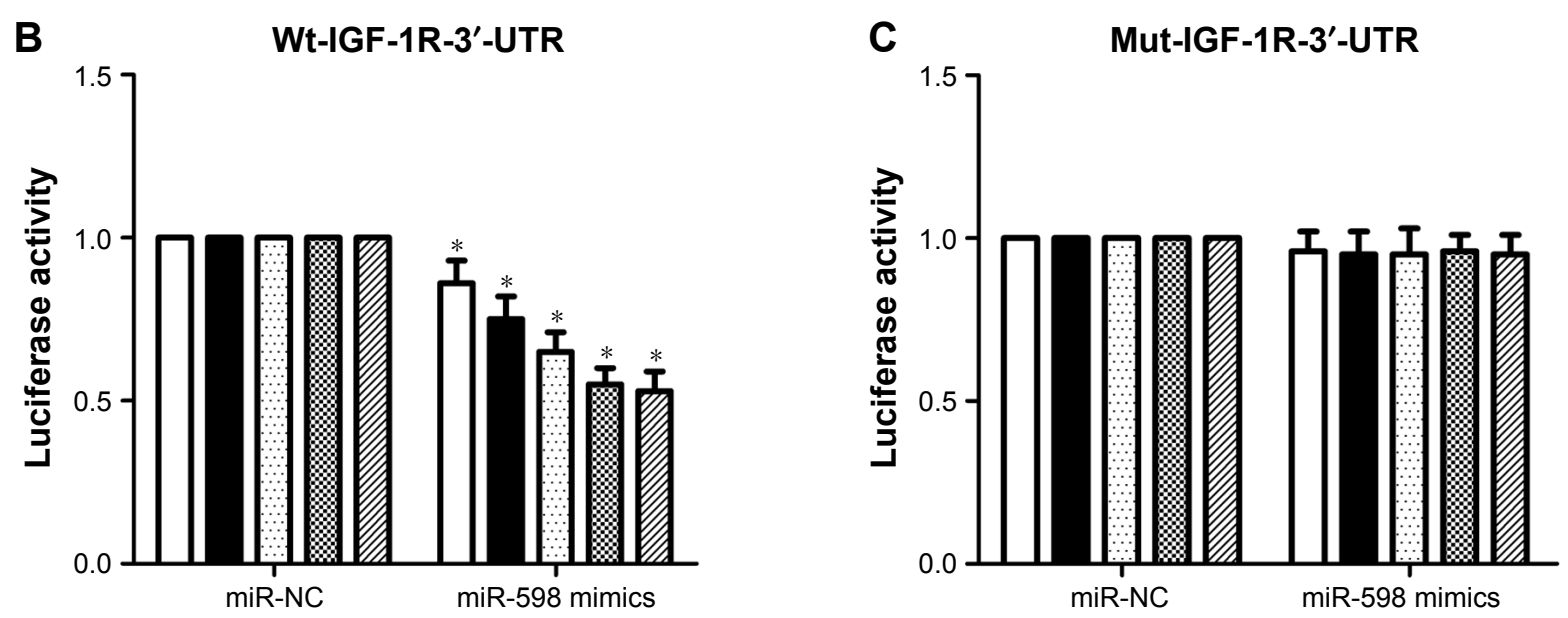

$\square 10 \mathrm{nM} \square 20 \mathrm{nM} \square 30 \mathrm{nM} \quad 40 \mathrm{nM}$

D

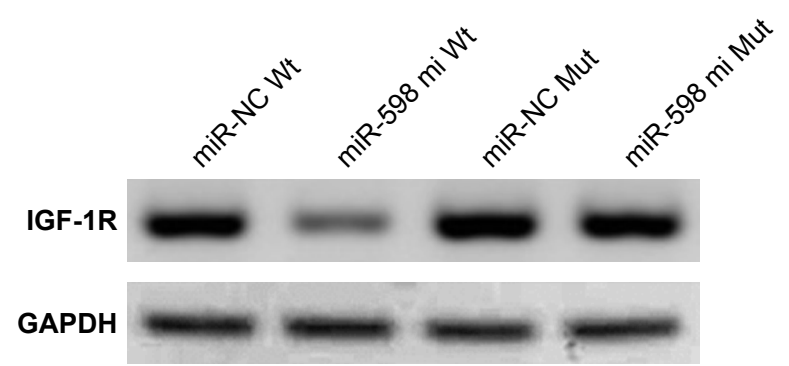

$\mathbf{F}$

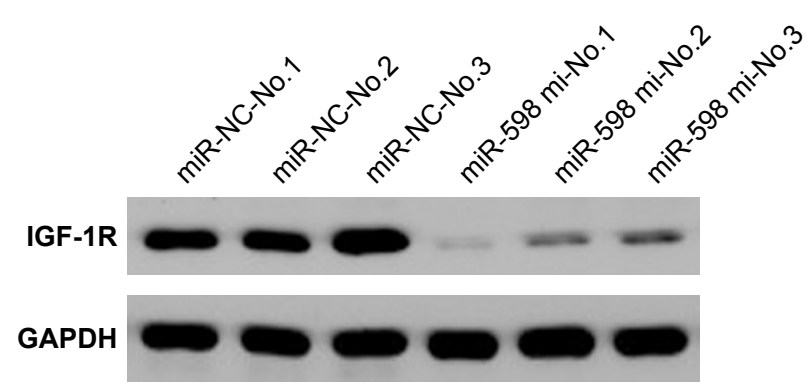

$\mathbf{E}$

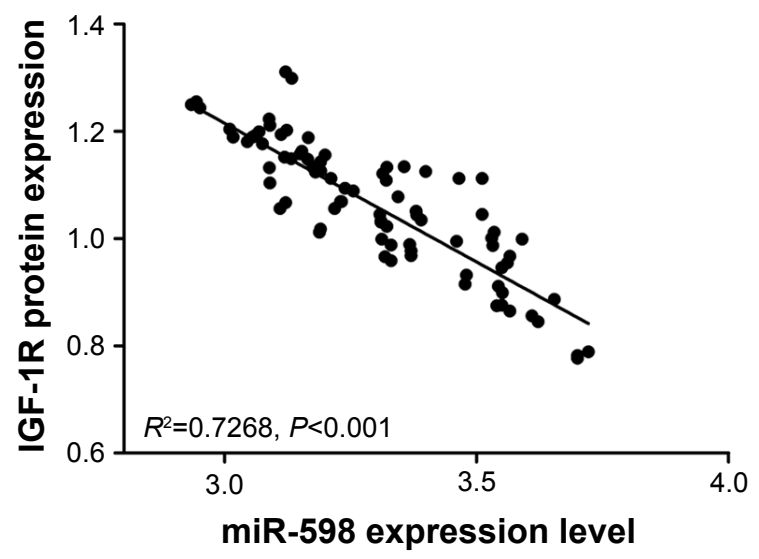

BGC-823

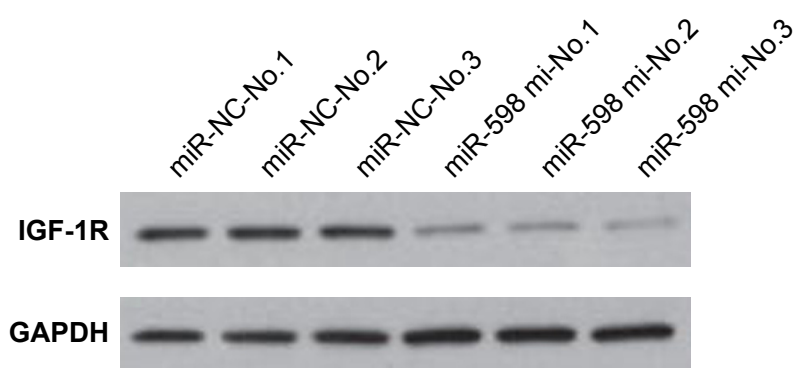

Figure 5 IGF-IR is a direct target of miR-598.

Notes: (A) Seed sequences of miR-598 in the 3'-UTR of IGF-IR. (B, C) Luciferase reporter assay data showed that co-transfecting cells with miR-598 and Wt-IGF-IR$3^{\prime}$-UTR produced a significant decrease in luciferase activity, whereas co-transfection with the Mut-IGF-IR-3'-UTR and miR-598 mimics demonstrated no difference compared with the control group. Data are presented as mean \pm SD of at least three independent experiments $* P<0.05$ vs negative control miRNAs (miR-NC). (D) The IGF-IR protein expression in HEK293T cells transfected with miR-598 mimics was detected by Western blotting analysis. (E) An inverse correlation between the expressions of miR-598 and IGF-IR proteins in gastric cancer tissues was identified. (F) All mice in this study were euthanized by way of cervical traction. The expression of IGF-IR protein in tumor mass was detected by Western blot. $* P<0.05$, vs control. miR-598-No.I, No.2 and No.3: the number of mice with transfection of miR-598. miR-NC-No. I, No.2 and No.3: the number of mice with transfection of miR-NC.

Abbreviations: $\mathrm{Wt}$, wild-type; Mut, mutant; mi, mimic. 
A

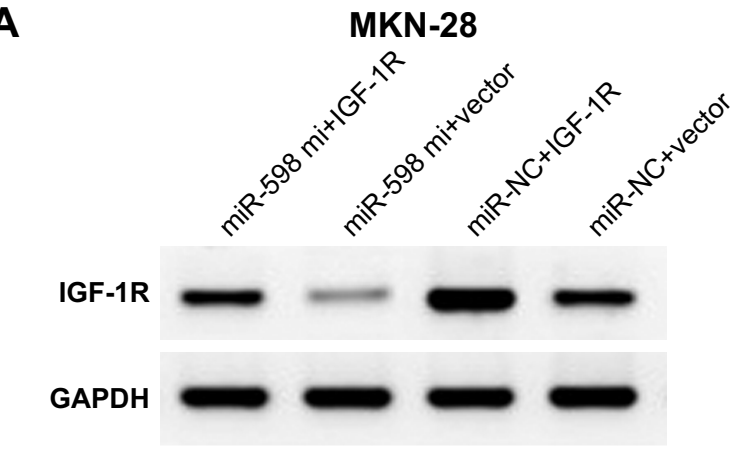

B

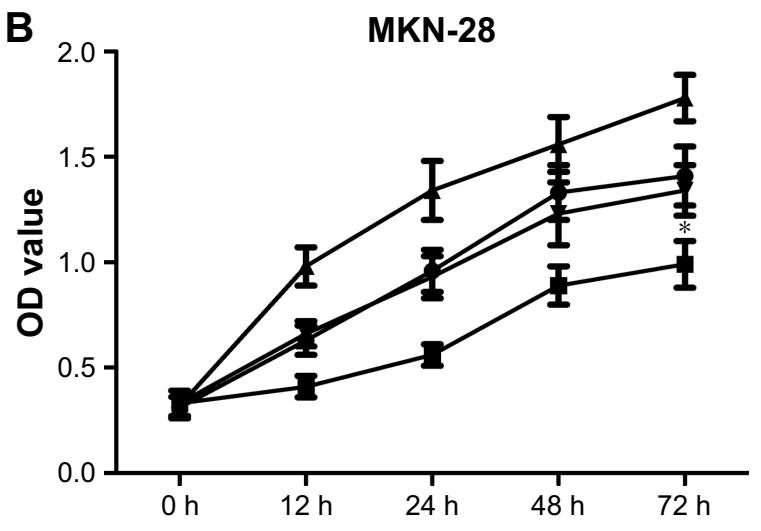

BGC-823

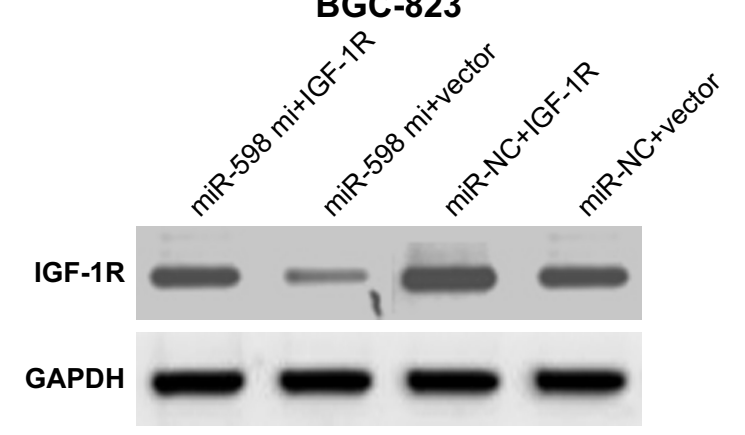

BGC-823

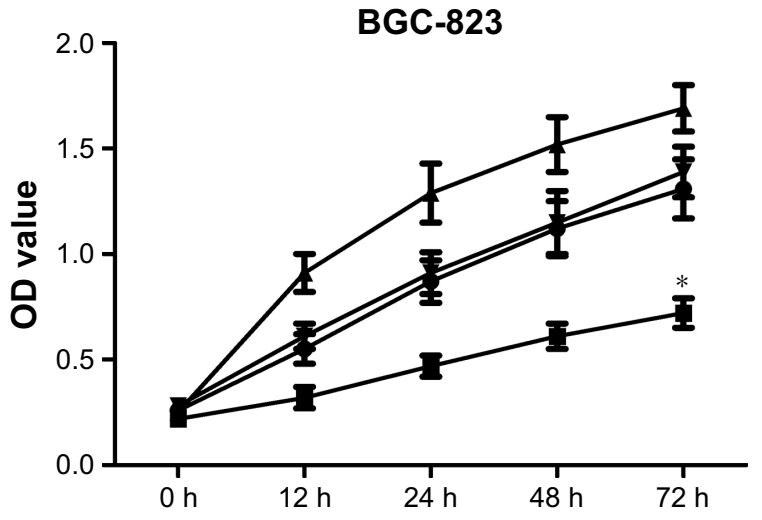

$\rightarrow$ miR-598 mi+IGF-1R $\rightarrow$ miR-598 mi+vector $\neq$ miR-NC+IGF-1R $\rightarrow$ miR-NC+vector
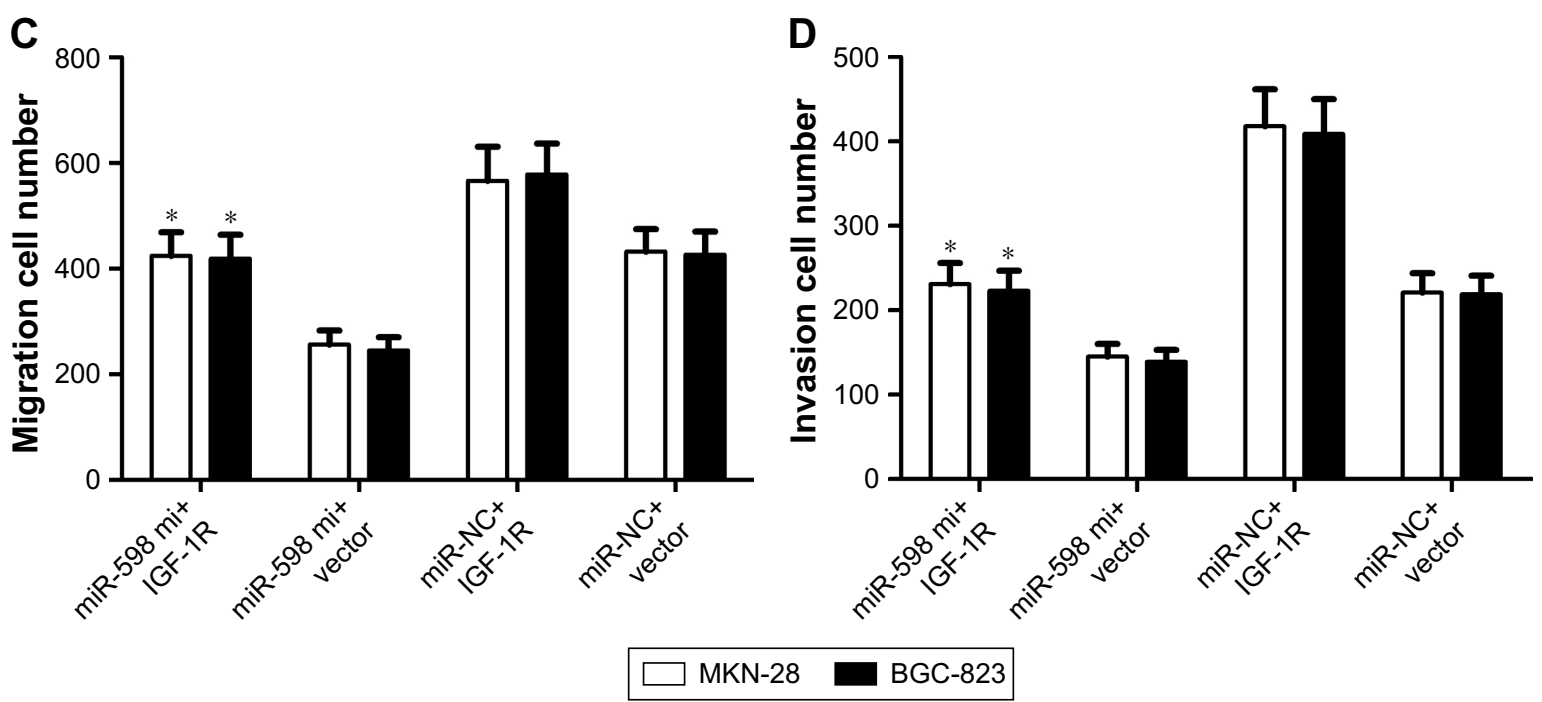

Figure 6 IGF-IR overexpression reverses the inhibitory effects of miR-598.

Notes: (A) MKN-28 and BGC-823 cells were transfected with miR-598 mimic or negative control miRNAs (miR-NC), and then co-transfected with IGF-IR plasmid or vector. Western blot analysis was conducted to measure the protein expression of IGF-IR. (B) Cell proliferation was determined in MKN-28 and BGC-823 cells by MTT assay. (C, D). Transwell assays were performed to measure the migration and invasion using crystal violet staining, and then cell invasion was determined. $* P<0.05$ vs miR-NC or vector. Abbreviation: mi, mimic.

\section{IGF-IR inhibition aggravates the} inhibitory effects of miR-598

Eventually, to determine whether miR-598 repressed the progression of GC by targeting IGF-1R, we carried out IGF-1R silencing assay, and transfected IGF-1R siRNA and control siRNA into MKN-28 and BGC-823 cells with miR-598 mimics, and further investigated the role of IGF-1R in miR-598-mediated proliferation, migration, and invasion (Figure 7A). We found that silencing of IGF-1R markedly aggravated miR-598-inhibited MKN-28 and BGC-823 cell proliferation, migration, and invasion $(P<0.05$; Figure 7B-D). These findings indicate that IGF-1R mediates the biological functions of miR-598 in GC cells. 
A

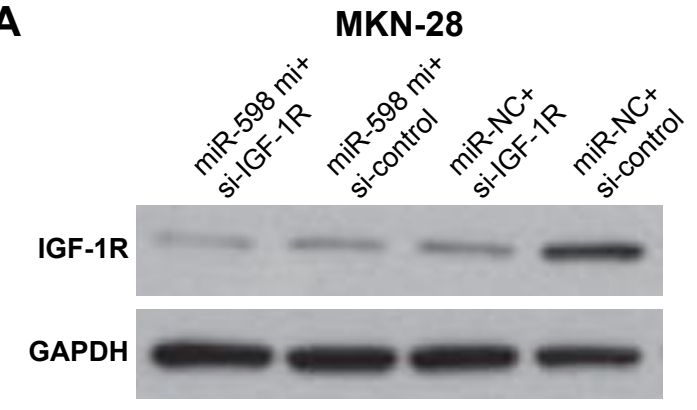

B

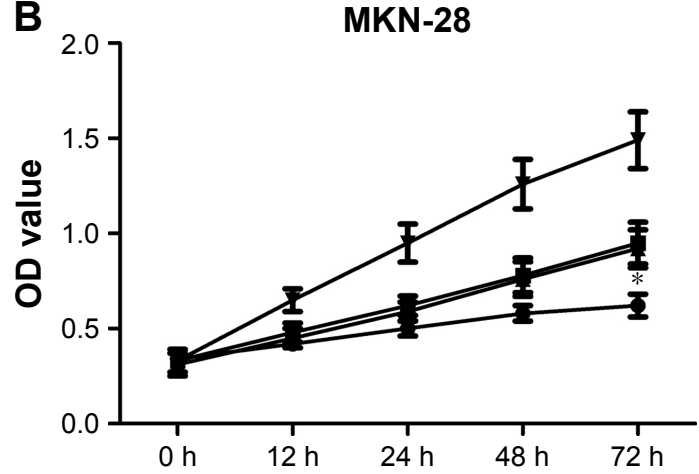

BGC-823

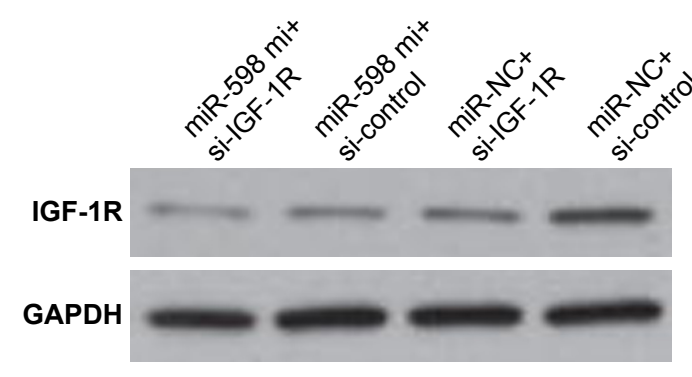

BGC-823

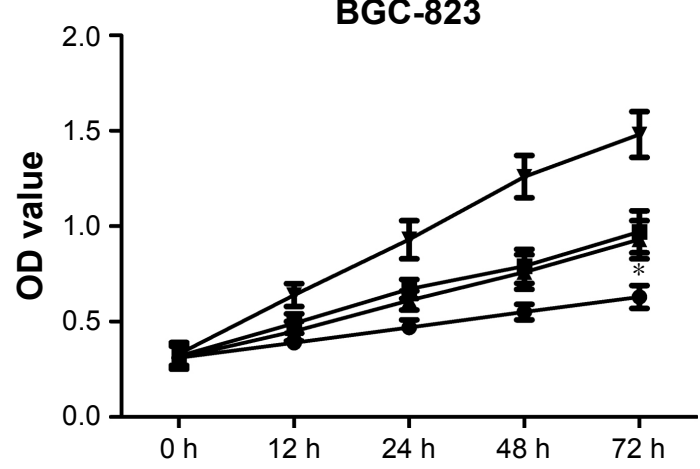

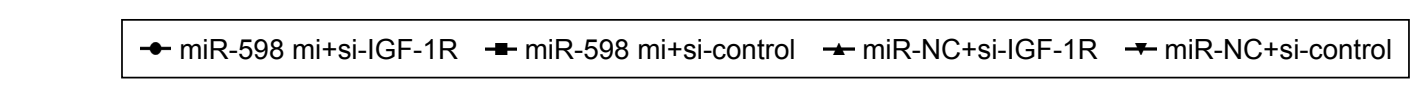

C

C
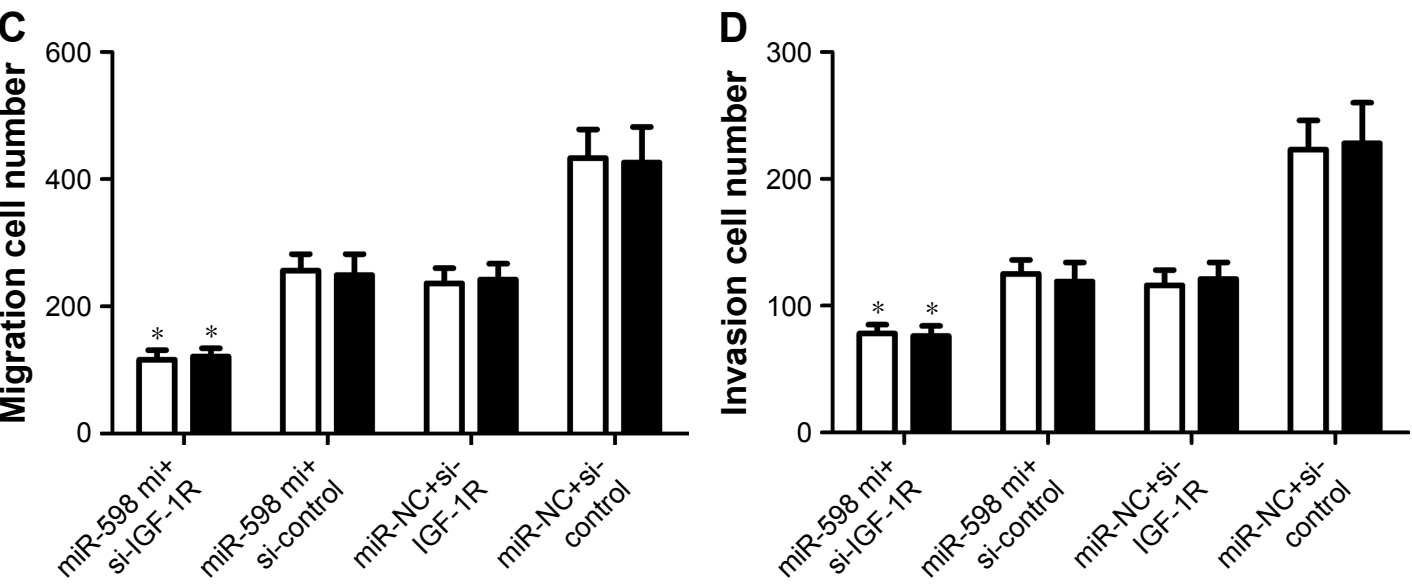

MKN-28

BGC-823

Figure 7 Silencing of IGF-IR aggravates inhibitory effects of miR-598.

Notes: (A) MKN-28 and BGC-823 cells were transfected with miR-598 mimic or negative control miRNAs (miR-NC), and then co-transfected with IGF-IR siRNAs or control siRNAs. Western blot analysis was conducted to measure the protein expression of IGF-IR. (B) Cell proliferation was determined in MKN-28 and BGC-823 cells by MTT assay. (C, D). Transwell assays were performed to measure the migration and invasion using crystal violet staining, and then cell invasion was determined. $* P<0.05$ vs miR-NC or si-control.

Abbreviation: mi, mimic.

\section{Discussion}

In recent years, the treatment of GC patients has mainly included surgery, chemotherapy, and radiotherapy; however, long-term survival status has remained unsatisfactory. ${ }^{3,4}$ It has been reported that TNM stage, lymph node involvement, and metastasis were the putative standards for surgical options and prognosis prediction of GC patients. ${ }^{5,6}$ In recent studies, molecular profiling has contributed to our understanding of the progression and potential targets of multiple human cancers. Molecular biomarkers are not only used for diagnosis but also act as potential therapeutic targets. MiR-598 has been reported to serve as a biomarker in a couple of cancers. ${ }^{12,19,20}$ However, the specific role and mechanism of miR-598 in GC progression is rarely explored.

In the present study, we found that miR-598 expression level was significantly downregulated in GC tissues 
compared to non-tumor tissues, and correlated with poor prognosis, vascular invasion, TNM stage, and lymph node metastases as well as IGF-1R expression. In addition, miR-598 expression was also downregulated in three GC cell lines. Consistent with our results, Wang et al demonstrated that miR-598 expression is significantly downregulated in glioblastoma tissues and cell lines. ${ }^{21}$ Chen et al found that downregulation of miR-598 is a frequent event in colorectal cancer tissues compared with the para-carcinoma tissues. ${ }^{19}$ These results indicate that miR-598 may exert an inhibitory effect on the tumor biology of GC cells.

miRNAs are a kind of small non-coding RNAs, and play an important role in the development of GC. ${ }^{7}$ miRNAs are able to precisely bind the $3^{\prime}$-UTR of their target mRNAs, and trigger the degradation or translation inhibition of mRNAs. ${ }^{9}$ To elucidate the mechanisms underlying miR-598-inhibited GC progression, we selected potential targets of miR-598 in GC cells. Of candidate target genes, we found IGF-1R was involved in the progression of GC in our previous study. ${ }^{16}$ As reported, IGF-1R overexpression can be found in many types of cancers, such as colorectal cancer and lung cancer. ${ }^{22-24}$ A couple of reports identified that inhibition of IGF-1R exerts anti-tumor effects, therefore, IGF-1R has been suggested as a novel therapeutic target for GC patients. ${ }^{16}$

In this study, IGF-1R mRNA and protein expressions were significantly increased in GC tissues compared to non-tumor tissues, and its protein expression negatively correlated with miR-598 expression in GC samples. Besides, the luciferase reporter assay indicated that miR-598 directly bound the 3'-UTR of IGF-1R mRNA, and suppressed IGF-1R expression at the post-transcriptional level. Most importantly, up-regulation of IGF-1R markedly reversed the inhibitory effects of miR-598 on the proliferation, migration, and invasion of GC cells, while inhibition of IGF-1R aggravated miR-598 inhibitory effects. Consistent with our results, Wang et al found that miR-598 plays a tumor suppressor role in glioblastoma, and that its anti-oncogenic effects are mediated directly via the inhibition of MACC1 expression and modulation of Met/AKT pathways. ${ }^{21}$ Chen et al also suggested that miR-598 regulates epithelial-mesenchymal transitions by directly repressing its downstream target gene JAG1, to inactivate Notch signaling pathway in colorectal cancer. ${ }^{19}$ These results indicate that IGF-1R indeed acts as a downstream effector in miR-598-repressed GC proliferation, migration, and invasion.

Our study has several limitations. Firstly, the endogenous expression level of miR-598 is not high enough, thus, only miR-598 overexpression assay was investigated in this study. Secondly, more samples or cell lines need to be used to identify the real expression level of miR-598. Thirdly, we demonstrated that the phosphorylation level of putative IGF1R-related molecules ERK1/2 and Akt were significantly decreased in miR-598-overexpressing MKN-28 and BGC823 cells; however, other potential molecules involved in miR-598-IGF-1R pathway were not investigated at this time. So, more studies on miR-598 and GC need to be conducted in the near future.

In conclusion, miR-598 is downregulated in GC tissues, and cell lines and exerts tumor-suppressing functions via directly targeting IGF-1R. The present study may provide new insights to the molecular mechanisms underlying GC development and progression. Thus, miR-598 may be used as a promising therapeutic target for GC.

\section{Acknowledgment}

We are thankful to other members in our laboratory for their suggestions.

\section{Disclosure}

The authors report no conflicts of interest in this work.

\section{References}

1. Coniglio A, Tiberio GA, Busti M, et al. Surgical treatment for gastric carcinoma in the elderly. J Surg Oncol. 2004;88(4):201-205.

2. Inoue H, Matsuyama A, Mimori K, Ueo H, Mori M. Prognostic score of gastric cancer determined by cDNA microarray. Clin Cancer Res. 2002; 8(11):3475-3479.

3. Uemura N, Kikuchi S, Sato Y, et al. A phase II study of modified docetaxel, cisplatin, and S-1 (mDCS) chemotherapy for unresectable advanced gastric cancer. Cancer Chemother Pharmacol. 2017;80(4): 707-713.

4. Alderson D, Cunningham D, Nankivell M, et al. Neoadjuvant cisplatin and fluorouracil versus epirubicin, cisplatin, and capecitabine followed by resection in patients with oesophageal adenocarcinoma (UK MRC OE05): an open-label, randomised phase 3 trial. Lancet Oncol. 2017;18(9):1249-1260.

5. Satake H, Kondo M, Mizumoto M, et al. Phase I study of neoadjuvant chemotherapy with capecitabine and oxaliplatin for locally advanced gastric cancer. Anticancer Res. 2017;37(7):3703-3710.

6. Pant S, Patel M, Kurkjian C, et al. A Phase II study of the c-Met inhibitor tivantinib in combination with FOLFOX for the treatment of patients with previously untreated metastatic adenocarcinoma of the distal esophagus, gastroesophageal junction, or stomach. Cancer Invest. 2017;35(7):463-472.

7. Huang LX, Hu CY, Jing L, et al. microRNA-219-5p inhibits epithelial-mesenchymal transition and metastasis of colorectal cancer by targeting lymphoid enhancer-binding factor 1. Cancer Sci. 2017; 108(10):1985-1995.

8. Guo L, Huang X, Liang P, et al. Role of XIST/miR-29a/LIN28A pathway in denatured dermis and human skin fibroblasts (HSFs) after thermal injury. J Cell Biochem. 2018;119(2):1463-1474.

9. Zeng $\mathrm{Y}$, Wang $\mathrm{KX}, \mathrm{Xu} \mathrm{H}$, Hong $\mathrm{Y}$. Integrative miRNA analysis identifies hsa-miR-3154, hsa-miR-7-3, and hsa-miR-600 as potential prognostic biomarker for cervical cancer. J Cell Biochem. 2018;119(2): $1558-1566$.

10. Liang L, Gao C, Li Y, et al. miR-125a-3p/FUT5-FUT6 axis mediates colorectal cancer cell proliferation, migration, invasion and pathological angiogenesis via PI3K-Akt pathway. Cell Death Dis. 2017;8(8): e2968. 
11. Pei ZJ, Zhang ZG, Hu AX, Yang F, Gai Y. miR-122-5p inhibits tumor cell proliferation and induces apoptosis by targeting MYC in gastric cancer cells. Pharmazie. 2017;72(6):344-347.

12. Liu K, Sun X, Zhang Y, Liu L, Yuan Q. MiR-598: A tumor suppressor with biomarker significance in osteosarcoma. Life Sci. 2017;188: $141-148$

13. Liu MD, Wu H, Wang S, et al. MiR-1275 promotes cell migration, invasion and proliferation in squamous cell carcinoma of head and neck via up-regulating IGF-1R and CCR7. Gene. 2018;646:1-7.

14. Tu C, Wang F, Wan J. MicroRNA-381 inhibits cell proliferation and invasion in endometrial carcinoma by targeting the IGF-1R. Mol Med Rep. 2018;17(3):4090-4098.

15. He L, Zhang S, Zhang X, et al. Effects of insulin analogs and glucagonlike peptide-1 receptor agonists on proliferation and cellular energy metabolism in papillary thyroid cancer. Onco Targets Ther. 2017;10: 5621-5631.

16. Wang H, Wang C, Tian W, Yao Y. The crucial role of SRPK1 in IGF1-induced EMT of human gastric cancer. Oncotarget. 2017;8(42): 72157-72166.

17. Girnita L, Shenoy SK, Sehat B, et al. Beta-arrestin and Mdm2 mediate IGF-1 receptor-stimulated ERK activation and cell cycle progression. J Biol Chem. 2007;282(15):11329-11338.
18. Duan L, Maki CG. The IGF-1R/AKT pathway determines cell fate in response to p53. Transl Cancer Res. 2016;5(6):664-675.

19. Chen J, Zhang H, Chen Y, et al. miR-598 inhibits metastasis in colorectal cancer by suppressing JAG1/Notch2 pathway stimulating EMT. Exp Cell Res. 2017;352(1):104-112.

20. Mosakhani N, Guled M, Leen G, et al. An integrated analysis of miRNA and gene copy numbers in xenografts of Ewing's sarcoma. J Exp Clin Cancer Res. 2012;31:24.

21. Wang N, Zhang Y, Liang H. microRNA-598 inhibits cell proliferation and invasion of glioblastoma by directly targeting metastasis associated in colon cancer-1. Oncol Res. Epub 2018 Feb 14.

22. Goel A. IGF-1R: SUMO-ing its weight in chemoresistant colorectal cancer. Br J Cancer. 2017;117(12):1733-1735.

23. Codony-Servat J, Cuatrecasas M, Asensio E, et al. Nuclear IGF-1R predicts chemotherapy and targeted therapy resistance in metastatic colorectal cancer. Br J Cancer. 2017;117(12):1777-1786.

24. Wilson C, Nimick M, Nehoff H, Ashton JC. ALK and IGF-1R as independent targets in crizotinib resistant lung cancer. Sci Rep. 2017 $7(1): 13955$.
OncoTargets and Therapy

\section{Publish your work in this journal}

OncoTargets and Therapy is an international, peer-reviewed, open access journal focusing on the pathological basis of all cancers, potential targets for therapy and treatment protocols employed to improve the management of cancer patients. The journal also focuses on the impact of management programs and new therapeutic agents and protocols on

\section{Dovepress}

patient perspectives such as quality of life, adherence and satisfaction. The manuscript management system is completely online and includes a very quick and fair peer-review system, which is all easy to use. Visit http://www.dovepress.com/testimonials.php to read real quotes from published authors. 